\title{
Non-Neoplastic Pancreatic Disorder
}

National Cancer Institute

\section{Source}

National Cancer Institute. Non-Neoplastic Pancreatic Disorder. NCI Thesaurus. Code C53505.

A non-neoplastic disorder that affects the pancreas. Representative examples include pancreatitis and pancreatic insufficiency. 